\title{
Burnout Among Nurses: The Impact of Personal Factors of Attachment Avoidance and Attachment Anxiety
}

\author{
Khansa Fadhilah Noorputeri ${ }^{1}$ Zamralita Zamralita ${ }^{1}$ Daniel Lie $^{1 *}$ \\ ${ }^{1}$ Faculty of Psychology, Universitas Tarumanagara, Jakarta, Indonesia \\ "Corresponding author. Email: daniell@fpsi.untar.ac.id
}

\begin{abstract}
Nurse is among of many professions with a high workload, which is vulnerable to a state of burnout. Personal factors, such as attachment avoidance and attachment anxiety, are identified as the factors that affect burnout and it is necessary to be managed properly. The aim of this study is to examine the impact of attachment avoidance and attachment anxiety towards burnout among nurses. This research was conducted using quantitative method, through the distribution of questionnaires involving 112 active nurses working at Hospital X in Jakarta. The Burnout Assessment Tool developed by Schaufeli et al. (2020) and The Experiences in Close Relationships Relationship Structures by Fraley et al. (2011) were used to measure the burnout and attachment styles respectively. Regression test analysis reveals that there is a significant impact of attachment anxiety on burnout $(F=4.674 ; p=0.033<0.05)$ and there is no significant impact on the attachment avoidance. This study has theoretical and practical implications.
\end{abstract}

\section{Keywords: Attachment avoidance, attachment anxiety, burnout, nurses}

\section{INTRODUCTION}

Nurse is among many professions that plays an important role in providing health services for the community. In line with their essential role, they also have quite large job demands. Nurses are required to take care chronic patients in an irregular work shift, are responsible to establish a good relationship and contact with patients as well as their families as to promote their well-beings, and constantly dealing with suffering and even death patients [1], [2].

All of these demands experienced by nurses will increase during the Coronavirus Disease (COVID-19) pandemic, in which nurses are one of the professions on the frontline against the COVID-19 pandemic. A study conducted by Lai et al. [3] shows that healthcare professionals in Wuhan, especially nurses and frontline workers, experienced the highest psychological burden in late January 2020. The Quebec Nurse Union recorded at least 1700 nurses had already quit in the first four months of the pandemic because they had to work under pressure every day [4]. Similarly, Washington hospitals face a shortage of nurses during the pandemic as the number of Covid-19 patients is still on the rise [5]. Furthermore, Zerbini et al. [6] identified how German nurses working in COVID-19 wards reported worse burnout scores compared to their colleagues in regular wards. Recently, a research was conducted by a research team from the Master of Occupational Medicine Study Program, Faculty of Medicine, University of Indonesia (MKK FKUI) revealed that $83 \%$ of health workers which includes nurses in Indonesia experienced moderate to high burnout due to the COVID-19 pandemic [7].
According to Schaufeli et al. burnout is defined as a mental disorder characterized by severe mental exhaustion, a person who experiences burnout cannot handle it without the help or assistance of others [8]. Although there are various definitions of burnout, experts consider exhaustion to be its core characteristic[8]. Burnout is characterized by four dimensions exhaustion, mental distance, cognitive impairment and emotional impairment [8]. Exhaustion is defined as a large loss of energy and results in physical and mental. Mental distance is when a person psychologically withdraws from work. Emotional impairment makes a person show intense emotional reactions. Cognitive impairment is characterized by poor cognitive performance [8].

Burnout is an important worker-related issue to be discussed. Research has proven its effect on a person's physical and psychological condition. Burnout can causes cardiovascular disease depressive symptoms and insomnia [9], [10], [11], [12], [13]. In work, burnout also has a detrimental effect, including reduced job performance and job satisfaction, absence, and increased turnover intention [14], [15], [16], [17]. If all these happen to nurses, their work focus will be disrupted and will result to the decreasing quality of health services that is needed during this pandemic.

In order to prevent burnout in the workplace, it is important to know the factors that affect burnout. Negri [18] in her research stated that there is a need to identify effective methods in dealing with stress and demands associated with burnout clearly. McVicar [19] explained that there is a need for a research examining the personal factors of nurses that exacerbate workplace stress. Personal vulnerability factors 
(or personal demands) force individuals to invest effort in their work and are therefore associated with physical and psychological costs [20]. In line with McVicar's [19] and Barbier et al's [20] explanation, Blustein suggests further research to see how individual differences in relational functions can predict various aspects of work behavior [21]. Blustein argues that work is an inherently relational act, and that every decision, experience, or interaction in work is understood, influenced, and shaped by relationships [21]. This could mean there is association between personal factors and burnout and this association can be explained with attachment style theory.

Attachment style is defined as a reciprocal emotional bond between individuals from infancy with primary caregivers that lasts a long time and each contributes to the quality of the relationship [22]. Not only plays a role in explaining the relationship between babies and their parents but also the emotional relationship of individuals as adults. Early experiences related to the interaction of infants with their parents are an important part of forming an individual's internal working model or mental model [23]. Attachment style theory looks at individual differences in internal working models, which is the representations of how individuals relate to others who are close to them. In addition, attachment style can produce specific predictions regarding an individual's capacity to regulate emotions and deal with stress in a social context [24]. In adults, these internal working models are very likely to be activated in times of stress, they form the basis for cognitive and affective assessments of stressful events and a person's behavioural responses to these events [25]. The attachment style that is formed in a person plays a role in personality development and guides subsequent social behaviour. It also affects the functioning of adults, including in work [26], [27].

The attachment style is divided into two dimensions namely attachment avoidance and attachment anxiety [28]. The avoidance dimension reflects how individuals do not have trust in relationships, good intentions of others, and tend to try to maintain independence and provide emotional distance to others [29]. Individuals with high attachment avoidance scores have a negative model towards others, and make them distance themselves from suffering of others so that they sharply reduce their empathy and love [30]. They also do not like to be open or when other people open-up emotionally [31]. Individuals with a high level of attachment avoidance will tend to have a system of deactivating strategies, which involves efforts to avoid closeness with other people, as well as efforts to suppress or reduce threats that can activate the attachment system [30]. Furthermore, social interaction is also hampered due to negative thoughts and difficulty trusting others [32].

In contrast, individuals with high attachment anxiety scores have negative views of themselves and experience anxiety in their relationships [33]. They have a negative model of themselves as unlovable [30]. The anxiety dimension reflects how the individual feels worried and afraid that other people will not be present when needed [29]. Bartholomew explains that with attachment anxiety, a person becomes dependent on the acceptance of others and has a tendency to idealize others [32]. The level of attachment anxiety makes individuals tend to have a hyperactivating strategy system, which involves excessive efforts to achieve support and closeness in relationships, as well as a deep fear of rejection by others [30]. According to Hazan and Shaver, individuals with attachment anxiety have excessive concern about rejection by co-workers and worry about the approval of others at work [26].

Although attachment avoidance and attachment anxiety have opposite behavioural characteristics, they both involve a great deal of effort and consume energy that trigger burnout. A person with a high score on attachment avoidance and anxiety shows a bad coping strategy [34]. Supported by Virga [35] who argues that high level of attachment avoidance and attachment anxiety of an individual could become personal demands that through special mechanisms contributing to fatigue and burnout.

Previous literature studies have examined the effect of attachment style towards burnout. However, the result is mixed. For attachment anxiety dimension, West [25] reported that there was significant positive relationship between attachment anxiety and burnout. In contrast, Negri [18] reported the opposite. For attachment avoidance dimension, Negri [18] found that attachment avoidance affects burnout significantly but Mauender et al. concluded otherwise [36].

Based on the inconsistency results from previous studies have led the current researchers to re-examine the effect of attachment avoidance and attachment anxiety towards burnout. Such research has never been carried out on nurses as participants in Indonesia, especially during the COVID19 pandemic. Based on the information presented above, the proposed hypotheses are:

$\mathrm{H}_{1}$ : There is a significant impact of attachment avoidance on burnout among nurses.

$\mathrm{H}_{2}$ : There is a significant impact of attachment anxiety on burnout among nurses.

\section{METHODS}

Participants in this study were 112 nurses $(M=35,40$ years old; $78,6 \%$ women; $M=12.27$ years of working experience; $41.1 \%$ work in Intensive Care Unit/High Care Unit; $77.7 \%$ work as practitioner). This study adopted a quantitative and non-experimental research in which questionnaires were given to the participants.

\subsection{Scale of Burnout}

Burnout were measured using Burnout Assessment Tool (BAT) by Schaufeli et al. [8]. The items were translated and reviewed under three bilingual experts in the field of Industrial and Organizational Psychology. The questionnaire consists of 23 items describing four dimensions of exhaustion, mental distance, cognitive impairment, and emotional impairment. The exhaustion dimension consists of eight positive items. An example of an item on this dimension is "Ketika bekerja saya merasa 
lelah secara mental." The reliability test value on this dimension shows Cronbach's alpha value of 0.827 . The mental distance dimension consists of five positive points. An example of an item on this dimension is "Saya merasa tidak peduli terhadap pekerjaan saya". The reliability test value on this dimension shows Cronbach's alpha value of 0.687 . The cognitive impairment dimension consists of five positive points. An example of an item on this dimension is "Ketika bekerja, saya kesulitan untuk berpikir jernih". The reliability test value on this dimension shows Cronbach's alpha value of 0.864 . The emotional impairment dimension consists of five positive items. An example of an item on this dimension is "Saya kurang mampu mengontrol emosi ketika bekerja". The reliability test value on this dimension shows Cronbach's alpha value of 0.830. Participants answered the questionnaire with a Likert scale of 1 (Never) to 5 (Always).

\subsection{Scale of Attachment Style}

Attachment style were measured using the The Experiences in Close Relationships - Relationship Structures (ECR-RS) by Fraley et al. [28]. The items were translated and reviewed under three bilingual experts in the field of Industrial and Organizational Psychology. The questionnaire consists of nine items that measure two dimensions attachment avoidance and attachment anxiety. It measures four aspects relatioships such as mother, father, partner, and friend. Attachment avoidance dimensions are measured using six items. There are two positive items and four negative items. An example of a positive item from this dimension is "Saya tidak merasa nyaman terbuka dengan ibu saya" while an example of a negative item on this dimension is "Saya sering membicarakan banyak hal dengan ibu saya". The reliability test on the attachment avoidance dimension shows Cronbach's alpha value of 0.912 . The attachment anxiety dimension is measured using three positive items. An example of an item on this dimension is "Saya sering khawatir bahwa ibu saya tidak peduli dengan saya" Reliability tests on the attachment anxiety dimension showed a Cronbach's alpha value of 0.941. Participants answered the questionnaire with a Likert scale of 1 (Strongly disagree) to 7 (Strongly disagree).

\section{RESULT}

\subsection{Descriptive Statistics}

Burnout scores of the nurses are low $(M=1,87 ; S D=0,52)$. Similarly, the dimensions of burnout are also low. Moreover, the dimension of exhaustion has the highest mean among the four dimensions (exhaustion, $M=2,49, S D=0,68$; mental distance, $M=1,54, S D=0,59$; cognitive impairment, $M=$ $1,51, S D=0,58$; emotional, $M=1,51, S D=0,57$ ).

The overall mean score of attachment avoidance is low $(M$ $=2,98 ; S D=1,23)$. Furthermore, similar result was found when looking at every aspect. (mother, $M=2,92, S D=1,60$; father, $M=3,25, S D=1,83$; partner, $M=2,50, S D=1,56$; and friend, $M=3,27, S D=1,44$ ).

Likewise, the score of attachment anxiety among nurses is low too. $(M=2,98 ; S D=1,23)$ Among the four aspects, the aspect of relationship with partner has the highest score (mother, $M=3,8, S D=1,91$; father, $\mathrm{M}=3,64$, $\mathrm{SD}=1,99$; partner, $M=4,15, S D=2,00$; friend, $\mathrm{M}=3,54, \mathrm{SD}=1,80$ ).

\subsection{Hypotheses Analysis}

\subsubsection{Attachment avoidance}

Regression analysis is conducted to see the impact of attachment avoidance on burnout. Result shows $F=0.978$, $p=0.325$ (> 0.05), indicating that attachment avoidance does not affect significantly towards burnout.

\subsubsection{Attachment anxiety}

Regression analysis is conducted to see the impact of attachment anxiety on burnout. Result shows $F=4.674$, and $p=0.033(<0.05)$, indicating that attachment anxiety has a significant effect on burnout. Moreover, $R^{2}$ is 0.041 , indicating that attachment anxiety accounts for $4.1 \%$ of variance in burnout. The remaining $95.9 \%(100 \%-4.1 \%=$ $95.9 \%)$ is influenced by factors other than attachment anxiety.

\section{DISCUSSION}

This research has two hypotheses, First, there is a significant impact of attachment avoidance on burnout among nurses. However, result does not support the first hypothesis. One possible explanation for this finding relates to individuals reacting to stress, while individuals with attachment anxiety tend to hyper-activate their negative emotions, individuals with attachment avoidance tend to suppress their negative emotions [37]. They also assume that other people will not be available in stressful situations and tend to detached from work and co-workers [29]. However, individuals with attachment avoidance tend to minimize problems and avoid negative emotional experiences [31]. Thus, individuals with attachment avoidance could be disengaged but not necessarily burnout. [35].

Second, there is a significant impact of attachment anxiety on burnout among nurses and the results support it. In line with West [25] study that shows strong evidence regarding attachment anxiety which predicts higher burnout rates. This finding could be explained due to attachment anxiety that makes nurses tend to have hyperactivating strategies system, which involves excessive efforts to achieve support and closeness in the relationship, as well as a deep fear of rejection by others [30]. Similarly, according to Hazan and Shaver [26] individuals with attachment anxiety have excessive concern about rejection by co-workers and worry about the approval of others at work. Moreover attachment anxiety is associated with feelings of inferiority and 
insecurity [38]. This allows individuals with attachment anxiety levels to invest too much effort in the work to attract the attention and approval of others [26]. This will consume energy resources for the nurse and can result in burnout. Furthermore, when individuals seek to seek attention and approval from others in the workplace, they tend to experience lower levels of well-being when they do not obtain it [39].

Result indicates that aspect partner receives the highest score among the four aspects. Fraley et al. [28] stated that people may hold a different internal working model in each relationship. Hence, in this case, nurses could potentialy have past history of being rejected by his or her partner which eventually form a negative view towards their partner. With that, score of the aspect partner has the highest among the four.

Participants in this study were found to have low burnout scores, this could be explained by two reasons. First this is probably because some nurses have low attachment score. West reported that a low attachment score leads to negative effect of burnout [25]. This notion is accordance with the current result that participants have a low score on their attachment. Second, it is possible that nurses in this current research have high level of resilience, self-esteem or even social support. This could be true because multiple studies have shown that individuals who have those factors, tend to have a low level of burnout [40]-[42]

One of the limitations of this study is participants in this study were nurses who specifically working at Hospital X in Jakarta, so that the research participants were still limited and did not describe the nursing profession as a whole. Furthermore, this study examines only one personal factor that affects burnout among nurses and the strength of variable anxiety attachment explaining towards burnout is considered having small effect size. Although one may critisize the importance of the current research, it actually opens up many future research studies. For example, adding a mediator variable. In general, the existence of a mediator variable can strengthen the level of correlation of a relationship between the independent and the dependent variables [43]. Hence, future studies may include emotional regulation as a mediator because it has been shown to be associated with both attachments and burnout [44], [45].

Moreover, apart from mediator research, future studies could also focus on examining the impact of the four types of attachments on burnout. This study found that both attachment avoidance and attachment anxiety scores among nurses tended to be low. Apart from being categorized into two dimensions (attachment anxiety and avoidance), individual attachment scores can also be categorized into four types and they are: (a) secure, (b) dismissing, (c) preoccupied, and (d) fearful [28]. Lastly this study involved nurses as the participants because it was known as one of the professions with high demands and were very much needed at the time of the Covid-19 pandemic, future research studies need to be carried out on participants with different professions or demographic groups such as teachers who are experiencing work stresses during COVID-19 (e.g., conducting distance teaching virtually) [46].
Based on this finding, this research has several suggestions targeting to both hospital and nurses. For hospital management, it is important to increase their awareness about individuals' attachment style that could affect burnout. With that, hospitals will then comprehend on how to handle or manage their employees when they are experiencing high demands or perhaps to those employees who possess personal factors that are more susceptible to burnout. This awareness could eventually be one of many interventions to prevent burnout [18]. Moreover, it is further suggested to human resource division to use the attachment style measurement for employee recruitment and training. This measurement could help hospital to identify the types of attachment styles that their employees have. This method is further supported by Harms [31] who stated the importance of attachment style's measurement to be used in the workplace.

Moreover, it is recommended for nurses to understand their individual type of attachment styles. By knowing their own type of individual, nurses will then know more about themselves and this will aid them on how to react in certain situation so that burnout could be prevented. Last but not least, the current result indicates that exhaustion dimension has the highest score among the four dimensions of burnout. Thus, it is essential for nurses to take their time out from their busy schedule (e.g., participating in physical activity program), maintaining sleep patterns, or even getting support from colleagues [47]-[49].

\section{CONCLUSIONS}

The current research study yields two conclusions. First, attachment anxiety affects significantly on burnout. Second, there was no significant effect of attachment avoidance on burnout.

\section{REFERENCES}

[1] R. García-Sierra, J. Fernández-Castro, and F. Martínez-Zaragoza, "Relationship between job demand and burnout in nurses: does it depend on work engagement?," J. Nurs. Manag., vol. 24, no. 6, pp. 780788, 2016, doi: 10.1111/jonm. 12382.

[2] Z. Sablik, A. Samborska-Sablik, and J. Drozdz, "Universality of physicians' burnout syndrome as a result of experiencing difficulty in relationship with patients," Arch. Med. Sci., vol. 9, no. 3, pp. 398-403, 2013, doi: 10.5114/aoms.2012.28658.

[3] J. Lai et al., "Factors Associated With Mental Health Outcomes Among Health Care Workers Exposed to Coronavirus Disease 2019," JAMA Netw. open, vol. 3, no. 3, p. e203976, 2020, doi: 10.1001/jamanetworkopen. 2020.3976. 
[4] C. Van Vlaardingen, “1,700 Quebec nurses have quit during the pandemic, says union," 2020. https:// montreal.ctvnews.ca/1-700-quebec-nurses-have-quitduring-the-pandemic-says-union-1.5108013?cache $=$ hmytnewdupnwkw.

[5] N. Swaby, "Washington medical groups raise alarm over hospital capacity as COVID on the rise," 2021. https://www.king5.com/article/news/health/coronavirus /covid-19-cases-and-hospitalizations-on-the-rise-inwashington-state/281-d5b9097b-0c3c-45ea-a6dca189ebe3572f.

[6] Zerbini Giulia, Ebigbo Alanna, Reicherts Philipp, Kunz Miriam, and Messman Helmunt, "Psychosocial burden of healthcare professionals in timesof COVID-19 - a survey conducted at the University Hospital Augsburg," GMS Ger. Med. Sci., vol. 18, no. 1612-3174, pp. 1-9, 2020.

[7] HUMAS FKUI, " $83 \%$ Tenaga Kesehatan Indonesia Mengalami Burnout Syndrome Derajat Sedang dan Berat Selama Masa Pandemi COVID-19,” 2020. https://fk.ui.ac.id/berita/83-tenaga-kesehatan-indonesiamengalami-burnout-syndrome-derajat-sedang-danberat-selama-masa-pandemi-covid-19.html.

[8] W. Schaufeli, H. De Witte, and S. Desart, Manual Burnout Assessment Tool (BAT) - Version 2.0. KU Leuven, no. July. Belgium: Unpublished internal report, 2020.

[9] S. Toppinen-Tanner, K. Ahola, A. Koskinen, and A. Väänänen, "Burnout predicts hospitalization for mental and cardiovascular disorders: 10-Year prospective results from industrial sector," Stress Heal., vol. 25, no. 4, pp. 287-296, 2009, doi: 10.1002/smi.1282.

[10] S. Toker, S. Melamed, S. Berliner, D. Zeltser, and I. Shapira, "Burnout and risk of coronary heart disease: A prospective study of 8838 employees," Psychosom. Med., vol. 74, no. 8, pp. 840-847, 2012, doi: 10.1097/PSY.0b013e31826c3174.

[11] K. Ahola and J. Hakanen, "Job strain, burnout, and depressive symptoms: A prospective study among dentists," J. Affect. Disord., vol. 104, no. 1-3, pp. 103110, 2007, doi: 10.1016/j.jad.2007.03.004.

[12] R. Bianchi, I. S. a. Schonfeld, and E. Laurent, "Burnout does not help predict depression among French school teachers," Scand. J. Work. Environ. Health, vol. 41, no. 6, pp. 565-568, 2015, doi: 10.5271/sjweh.3522.

[13] G. Armon, A. Shirom, I. Shapira, and S. Melamed, "On the nature of burnout-insomnia relationships: A prospective study of employed adults," J. Psychosom.
Res., vol. 65, no. 1, pp. 5-12, 2008, doi: 10.1016/ j.jpsychores.2008.01.012.

[14] E. Demerouti, A. B. Bakker, and M. Leiter, "Burnout and job performance: The moderating role of selection, optimization, and compensation strategies," $J$. Occup. Health Psychol., vol. 19, no. 1, pp. 96-107, 2014, doi: 10.1037/a0035062.

[15] E. L. Lizano and M. Mor Barak, "Job burnout and affective wellbeing: A longitudinal study of burnout and job satisfaction among public child welfare workers," Child. Youth Serv. Rev., vol. 55, pp. 18-28, 2015, doi: 10.1016/j.childyouth.2015.05.005.

[16] W. B. Schaufeli, A. B. Bakker, and W. Van Rhenen, "How changes in job demands and resources predict burnout, work engagement, and sickness absenteeism.," J. Organ. Behav., vol. 30, no. 1, pp. 893-917, 2009, doi: 10.1002/job.

[17] W. B. Schaufeli and A. B. Bakker, "Job demands, job resources, and their relationship with burnout and engagement: a multi-sample study," SCHAUFELi, WILMAR B. BAKKER, ARNOLD B., vol. 25, no. October 2002, pp. 293-315, 2004.

[18] K. A. Negri, "Hardiness, adult attachment style, and burnout in nurses.," Diss. Abstr. Int. Sect. B Sci. Eng., vol. 79, no. 8-B(E), p. No-Specified, 2018, [Online]. Available: http://ovidsp.ovid.com/ovidweb.cgi?T=JS\& $\mathrm{PAGE}=$ reference $\& \mathrm{D}=\mathrm{psyc} 15 \& \mathrm{NEWS}=\mathrm{N} \& \mathrm{AN}=2018$ 26099-049.

[19] A. McVicar, "Workplace stress in nursing: A literature review," J. Adv. Nurs., vol. 44, no. 6, pp. 633642, 2003, doi: 10.1046/j.0309-2402.2003.02853.x.

[20] M. Barbier, I. Hansez, N. Chmiel, and E. Demerouti, "Performance expectations, personal resources, and job resources: How do they predict work engagement?," Eur. J. Work Organ. Psychol., vol. 22, no. 6, pp. 750762, 2013, doi: 10.1080/1359432X.2012.704675.

[21] D. L. Blustein, "A relational theory of working," $J$. Vocat. Behav., vol. 79, no. 1, pp. 1-17, 2011, doi: 10.1016/j.jvb.2010.10.004

[22] D. E. Papalia and G. Martorell, Experience Human Development, 14th ed. New York, NY: McGraw Hill, 2020.

[23] C. Hazan and P. Shaver, "INTERPERSONAL RELATIONS AND GROUP PROCESSES Romantic Love Conceptualized as an Attachment Process," $J$. Pers. Soc. Psychol., vol. 52, no. 3, pp. 511-524, 1987. 
[24] J. Bowlby, Attachment and Loss, Volume I: Attachment, vol. 1, no. 1. New York, 1969.

[25] A. L. West, "Associations Among Attachment Style, Burnout, and Compassion Fatigue in Health and Human Service Workers: A Systematic Review," J. Hum. Behav. Soc. Environ., vol. 25, no. 6, pp. 571-590, 2015, doi: 10.1080/10911359.2014.988321.

[26] C. Hazan and P. R. Shaver, "Love and Work: An Attachment-Theoretical Perspective," vol. 59, no. 2, pp. 270-280, 1990.

[27] J. A. Simpson, "Furnierschichtholz (LVL) Definitionen, Klassifizierung und Spezifikationen," Dintaschenb. 60 Holzwerkstoffe 1, vol. 59, no. 5, pp. 971980, 1990, doi: 10.1037//0022-3514.59.5.971.

[28] R. C. Fraley, M. E. Heffernan, A. M. Vicary, and C. C. Brumbaugh, "The Experiences in Close Relationships-Relationship Structures Questionnaire : A Method for Assessing Attachment Orientations Across The Experiences in Close Relationships - Relationship Structures Questionnaire: A Method for Assessing Attachment Orienta," no. March, 2011, doi: 10.1037/ a0022898.

[29] M. Mikulincer, P. R. Shaver, and P. R. Shaver, "Psychological Inquiry: An International Journal for the Advancement of Psychological Theory Boosting Attachment Security to Promote Mental Health , Prosocial Values, and Inter-Group Tolerance Boosting Attachment Security to Promote Mental Health , Proso," no. November 2014, pp. 37-41, 2007, doi: 10.1080/ 10478400701512646.

[30] M. Mikulincer and P. R. Shaver, "Attachment security, compassion, and altruism," Curr. Dir. Psychol. Sci., vol. 14, no. 1, pp. 34-38, 2005, doi: 10.1111/j.09637214.2005.00330.x

31] P. D. Harms, "Adult attachment styles in the workplace," Hum. Resour. Manag. Rev., vol. 21, no. 4, pp. 285-296, 2011, doi: 10.1016/j.hrmr.2010.10.006.

[32] K. Bartholomew and L. M. Horowitz, "Attachment Styles Among Young Adults: A Test of a Four-Category Model," J. Pers. Soc. Psychol., vol. 61, no. 2, pp. 226244, 1991, doi: 10.1037/0022-3514.61.2.226.

[33] D. A. Richards and A. C. H. Schat, "Attachment at (Not to) Work: Applying Attachment Theory to Explain Individual Behavior in Organizations," J. Appl. Psychol., vol. 96, no. 1, pp. 169-182, 2011, doi: 10.1037/ a0020372.
[34] A. M. Pines, "Adult attachment styles and their relationship to burnout: A preliminary, cross-cultural investigation," Work Stress, vol. 18, no. 1, pp. 66-80, 2004, doi: 10.1080/02678370310001645025.

[35] D. Vîrgă, W. B. Schaufeli, T. W. Taris, I. van Beek, and C. Sulea, "Attachment Styles and Employee Performance: The Mediating Role of Burnout," $J$. Psychol. Interdiscip. Appl., vol. 153, no. 4, pp. 383-401, 2019, doi: 10.1080/00223980.2018.1542375.

[36] R. G. Maunder et al., "Long-term psychological and occupational effects of providing hospital healthcare during SARS outbreak," Emerg. Infect. Dis., vol. 12, no. 12, pp. 1924-1932, 2006, doi: 10.3201/eid1212.060584.

[37] S. Ronen and M. Mikulincer, "Attachment orientations and job burnout: The mediating roles of team cohesion and organizational fairness," J. Soc. Pers. Relat., vol. 26, no. 4, pp. 549-567, 2009, doi: 10.1177/ 0265407509347930.

[38] M. Mikulincer and P. R. Shaver, "ScienceDirect The psychological effects of the contextual activation of security-enhancing mental representations in adulthood," Curr. Opin. Psychol., pp. 8-11, 2015, doi: 10.1016/j.copsyc.2015.01.008.

[39] A. Reizer, "Influence of employees attachment styles on their life satisfaction as mediated by job satisfaction and burnout," J. Psychol. Interdiscip. Appl., vol. 149, no. 4, pp. 356-377, 2015, doi: 10.1080/ 00223980.2014 .881312 .

[40] C. A. Connors, V. Dukhanin, A. L. March, J. A. Parks, M. Norvell, and A. W. Wu, "Peer support for nurses as second victims: Resilience, burnout, and job satisfaction," J. Patient Saf. Risk Manag., vol. 25, no. 1, pp. 22-28, 2020, doi: 10.1177/2516043519882517.

[41] A. R. Johnson, R. Jayappa, M. James, A. Kulnu, R. Kovayil, and B. Joseph, "Do Low Self-Esteem and High Stress Lead to Burnout Among Health-Care Workers? Evidence From a Tertiary Hospital in Bangalore, India," Saf. Health Work, vol. 11, no. 3, pp. 347-352, 2020, doi: 10.1016/j.shaw.2020.05.009.

[42] Y. Liu and Y. Aungsuroch, "Work stress, perceived social support, self-efficacy and burnout among Chinese registered nurses," J. Nurs. Manag., vol. 27, no. 7, pp. 1445-1453, 2019, doi: 10.1111/jonm.12828.

[43] R. M. Baron and D. A. Kenny, "The ModeratorMediator Variable Distinction in Social Psychological Research: Conceptual, Strategic, and Statistical Considerations," J. Pers. Soc. Psychol., vol. 51, no. 6, pp. 1173-1182, 1986, doi: 10.1007/BF02512353. 
[44] M. Akbari and S. M. Hossaini, "The relationship of spiritual health with quality of life, mental health, and burnout: The mediating role of emotional regulation," Iran. J. Psychiatry, vol. 13, no. 1, pp. 22-31, 2018.

[45] S. K. K. Nielsen, N. Lønfeldt, K. B. WolitzkyTaylor, I. Hageman, S. Vangkilde, and S. I. F. Daniel, "Adult attachment style and anxiety - The mediating role of emotion regulation," J. Affect. Disord., vol. 218, no. March, pp. 253-259, 2017, doi: 10.1016/j.jad.2017. 04.047 .

[46] F. Klapproth, L. Federkeil, F. Heinschke, and T. Jungmann, "Teachers experiences of stress and their coping strategies during COVID - 19 induced distance teaching," J. Pedagog. Res., vol. 4, no. 4, pp. 444-452, 2020, doi: 10.33902/jpr.2020062805.

[47] J. Dorrian, N. Lamond, C. Van Den Heuvel, J. Pincombe, A. E. Rogers, and D. Dawson, "A pilot study of the safety implications of Australian nurses' sleep and work hours," Chronobiol. Int., vol. 23, no. 6, pp. 11491163, 2006, doi: 10.1080/07420520601059615.

[48] M. J. Albar Marín and M. García-Ramírez, "Social support and emotional exhaustion among hospital nursing staff," Eur. J. Psychiatry, vol. 19, no. 2, pp. 96106, 2005, doi: 10.4321/S0213-61632005000200004.

[49] M.-H. Yao, "The relationships among work related stress, health status, and physical activity participation of nurses in teaching hospitals in Taipei, Taiwan," ProQuest Diss. Theses, no. May, p. 201, 2008, [Online]. Available: http://search.proquest.com/docview/ 304833781 ?accountid=14477\%5Cnhttps://nevada.ual.e s/biblioteca/gtb/sod/poa_login.php?centro=\$UALMG\& sid $=\$$ UALMG\&title $=\&$ atitle $=\&$ aulast $=$ Yao, + Ming Hui $\&$ date $=2008 \&$ volume $=\&$ issue $=\&$ pages $=$. 